\title{
Infrastructure, funding and follow-up in a programme of noninvasive ventilation
}

\author{
P. Leger*, G. Laier-Groeneveld ${ }^{\#}$
}

\begin{abstract}
Infrastructure, funding and follow-up in a programme of noninvasive ventilation. P. Leger, G. Laier-Groeneveld. (C) ERS Journals Ltd 2002.

ABSTRACT: Originating from centres charged with the care of patients with chronic respiratory insufficiency, noninvasive ventilation (NIV) has been used increasingly in chronic and acute respiratory failure during the last decade. Despite a considerable number of series and randomised studies advocating access to NIV for units that treat acute or chronic ventilatory failure, the number of units and the proportion of total ventilatory support remains poor. This is due to lack of education, as many units treat only a few patients per year. Indication, technique, education, monitoring and home care require special experience and a special environment and there is a wide range throughout Europe. With respect to home care in particular, there are many organisations, which range from totally private to hospital based or run for profit. A concerted action, funded by the European Union, will soon provide valuable information about the practice of home ventilation in Europe based on a European survey.

Eur Respir J 2002; 20: 1573-1578.
\end{abstract}

*Actions Médicales, Association Française Contre les Myopathies, Cedex, France. ${ }^{\#}$ Klinikum Erfurt 1. Medizinische Klinik, Zentrum für Pneumologie, Erfurt, Germany.

Correspondence: P. Leger, Actions Médicales, Association Française Contre les Myopathies, 1 Rue de l'Internationale, BP 5991002 EVRY Cedex, France. Fax: 33169472552 E-mail: pleger@afm.genethon.fr

Keywords: Acute respiratory failure, chronic respiratory failure, follow-up, noninvasive ventilation, organisation

Received: September 62002 Accepted: September 92002
In Europe, noninvasive ventilation (NIV) is usually implemented in a hospital environment, regardless of whether it is being used to treat patients with acute or chronic respiratory failure $(\mathrm{CRF})$. Therefore, when reviewing the infrastructure for NIV, it is necessary to discuss both the hospital and home environments. It is also important to appreciate that the organisation of care for patients needing NIV varies considerably depending on the indication and the country. The purpose of this article is to provide an overview of the infrastructure provided for the safe practice of NIV both in the hospital and the home. This review will discuss where NIV can be initiated, the criteria used to select patients, the necessary tools for implementing NIV and a framework for home care. This will be followed by a brief description of the funding for NIV and finally the follow-up necessary to assure a good outcome. The article will address the infrastructure for chronic NIV as well for acute use.
A concerted action, funded by the European Union, will soon report its findings and this will provide valuable information about the practice of home ventilation in Europe and act as a forum for the sharing of best practice.

\section{Where is noninvasive ventilation used in European hospitals and who initiates it?}

NIV originated, and is still based, in centres charged with the care of patients with chronic respiratory insufficiency (CRI), either for neuromuscular and chest wall disorders or together with pulmonary disease. Subsequently, there has been a large increase in the use of NIV for acute respiratory failure (ARF). This was initiated with its extensive use in acute exacerbations of chronic obstructive pulmonary disease (COPD), for which invasive ventilation

Previous articles in this series: No. 1: Brochard L, Mancebo J, Elliott MW. Noninvasive ventilation for acute respiratory failure. Eur Respir J 2002; 19: 712-721. No. 2: Ferrer M, Bernadich O, Nava S, Torres A. Noninvasive ventilation after intubation and mechanical ventilation. Eur Respir J 2002; 19: 959-965. No. 3: Elliott MW, Confalonieri M, Nava S. Where to perform noninvasive ventilation? Eur Respir J 2002; 19: 1159-1166. No. 4: Corrado A, Gorini M. Negative-pressure ventilation: is there still a role? Eur Respir J 2002; 20: 187-197. No. 5: Shneerson JM, Simonds AK. Noninvasive ventilation for chest wall and neuromuscular disorders. Eur Respir J 2002; 20: 480-487. No. 6: Wedzicha JA, Muir J-F. Noninvasive ventilation in chronic obstructive pulmonary disease, bronchiectasis and cystic fibrosis. Eur Respir J $2002 ; 20$ : 777-784. No. 7: Schönhofer B, Sortor-Leger S. Equipment needs for noninvasive mechanical ventilation. Eur Respir J 2002; 20: 1029-1036. No. 8: Nørregaard O. Noninvasive ventilation in children. Eur Respir J 2002; 20: 1332-1342. 
was restrictively indicated because of the presumed poor outcome. NIV provided an alternative. The expansion of the use of NIV both in acute and CRF was stimulated by the medical and financial benefits, which had been shown clearly when NIV was compared to invasive ventilation in selected patients [1-6]. However, despite its proven benefits, a number of studies have shown that the use of NIV as a proportion of total mechanical ventilation is nevertheless not widespread [7, 8]. In the time since these studies were published, it can be presumed that the use of NIV has steadily increased, both in percentage of mechanical ventilation and in units that incorporate the technique.

DoHerTy and GreEnstone [7] evaluated the availability of NIV in the UK and published their findings in 1998. They found that NIV was available in only $48 \%$ of hospitals and that patients could be transferred to another hospital for this treatment in another $7 \%$. Hospitals where NIV was available tended to serve a larger population and had more respiratory physicians than those where it was not. The authors found great regional variation in the availability of NIV. The survey suggested that the main reason for not implementing NIV was a lack of training of healthcare professionals in this form of treatment.

Even when NIV is available, it may not be used as much as clinical trial data suggests might be appropriate. In a survey performed by CARLUCCI et al. [8] in France, Switzerland and Spain, NIV was used prior to invasive ventilation in only $16 \%$ of cases. However, it can be assumed that there has been a considerable increase as experience grows and information and training spreads.

NIV for ARF is initiated in a wide variety of environments. This issue has been addressed in an earlier article in this series [9] and can be explained by the different organisation of healthcare in each country. For historical reasons, there is a wide range of specialists involved in NIV throughout Europe. These include intensivists or anaesthesiologists, pneumologists, paediatricians, generalists, and neurologists and rehabilitation physicians. In the study of Doherty and GreEnstone [7], NIV was initiated by respiratory physicians in $66 \%$ of cases and anaesthetists only $3 \%$ of the time.

The social healthcare systems in many European countries provide for the use of NIV in patients with CRF, but few countries have clear guidelines as to when NIV should be initiated and in which patient groups. Per capita, the use of NIV in the home has increased considerably in the last $6 \mathrm{yrs}$ in every European country [10]. For patients with CRF, NIV is usually implemented in pneumological units but sometimes in specialised rehabilitation units organised for ventilator-dependent patients. As ARF is frequent in the CRF patient population, it is also used in these units as patients deteriorate, modulated by the ability to admit intensive care patients or to have access to an intensive care unit (ICU). Conversely, the patient's initial presentation may be at in the emergency room or ICU. As a consequence some intensivists are also involved in the decision-making process or initiate
NIV for acute and more chronic patients. In a recent survey of hospitals in France, only $29 \%$ had a service dedicated to CRF and NIV. Of the 101 units that practise NIV, 56 were in a general nonteaching hospital and 45 were in a university hospital. The majority of NIV was initiated in pulmonary care units (74 out of 101) and the minority in medical or respiratory ICU's (27 out of 101) [11]. The level of experience varies considerably among the units that provide NIV. In the French study, only $46 \%$ of the units providing NIV treated $>10$ patients per year. In the UK study, which mainly focused on COPD, only $56 \%$ of the hospitals providing NIV treated more than ten patients per year [7]. There are no data concerning how many patients per year are needed to maintain skills, but if a unit providing NIV is unable to treat at least one patient per month, their ability to maintain an acceptable level of expertise, can be questioned.

\section{Criteria used to select patients}

In the study by Doherty and Greenstone [7], $80 \%$ of the responding hospitals used ABG to select patients for NIV in acute exacerbations of COPD. The criteria used varied and included different degrees of respiratory acidosis. Approximately 20\% of the centres used clinical indicators to select patients for acute treatment with NIV and these included exhaustion and failure to improve on standard treatment. There are few guidelines as to when NIV should be initiated in other patient groups, particularly in hypoxaemic ARF.

In a French survey of practice of domiciliary NIV in chronic ventilatory failure, prescription was based on the association of hypercarbia with symptoms, pulmonary function tests and evidence of nocturnal oxygen $\left(\mathrm{O}_{2}\right)$ desaturation in $73 \%$ of the units. Hypercarbia alone was the prime indication in only $19 \%$ of the units [11]. The majority of the patients proposed for chronic NIV were patients with restrictive disorders (such as scoliosis, mutilating sequelae of tuberculosis and neuromuscular patients) and this is the group that has demonstrated the most convincing benefits [12, 13]. These patients have typically been followed by hospital-based speciality units, able to provide a high level of competency in the areas of diagnosis, evaluation and long-term treatment including NIV. However, patients with COPD can develop chronic ventilatory failure despite maximum treatment including medication, rehabilitation and longterm oxygen therapy. By number, they form a much larger group and increasingly they are being offered chronic NIV. Some of these patients present with recurrent exacerbations which can be successfully treated with NIV acutely. The use of NIV at home on a long-term basis for this group of patients remains open to questioning [14].

\section{What is necessary for noninvasive ventilation?}

The results of randomised studies show that every hospital and ICU should have access to NIV as an 
option for assisted ventilation for CRI. Usually this should be in a specialised unit. The implementation of NIV needs expertise and it is important that the units treat a sufficient number of patients, a large scale of disorders and a broad range of severity. Some patients, particularly those with neuromuscular disease, also need education in secretion clearance techniques. They may need adaptations to other equipment, e.g. mounting of a ventilator on a wheelchair, transtracheal suctioning, choice of best tracheal canula and canula replacement, which is best done in a unit with experience of these kinds of problems.

For practical reasons, the implementation of longterm NIV is usually carried out over a few days (3-4) of hospitalisation, but this is not always necessary and NIV can be successfully initiated in the home, provided that there is a dedicated team able to spend sufficient time educating the patient and any carers. Access to support and advice should always be available, especially in disorders with a tendency to change. A motivated and trained medical team, aware of the indications and contraindications for NIV, will help to select the patients most likely to succeed with NIV. Achieving patient motivation and cooperation are also essential for success. Depending on local custom and regulations, NIV is initiated by physicians, nursing staff or physiotherapists. Given the pressures in reducing the number of physicians across the European Union, it is unlikely that most facilities will be able to provide 24 -h coverage by doctors fully trained in NIV. Therefore, nurses and/or physiotherapists will probably become more important in the delivery of this service, particularly for ARF. NIV is time consuming, at least initially, to explain the principles, benefits and potential adverse effects to the patient, and to select and adjust interfaces and ventilator settings. Particularly when beginning with NIV, the patient requires close supervision. Hospitalisation has the advantage of an on-site team, able to help the patient adapt to NIV quickly, with rapid resolution of any technical problems, regular coaching and encouragement by nurses and therapists. This helps to create patient confidence, specifically to get the patient to sleep with NIV, limits adverse effects and leads to a more rapid improvement in any symptoms and hypercarbia.

NIV is usually initiated by observing the patient on ventilation during the day, awake and during a nap, with continuous monitoring of $\mathrm{O}_{2}$ saturation and sometimes transcutaneous carbon dioxide $\left(\mathrm{CO}_{2}\right)$. Arterial blood gas tensions (ABG) should be measured after $1-2 \mathrm{~h}$ of NIV. Further monitoring of arterial $\mathrm{O}_{2}$ saturation with pulse oximetry $\left(\mathrm{Sp}, \mathrm{O}_{2}\right)$ with or without continuous $\mathrm{CO}_{2}$ monitoring is recommended during sleep, with a follow-up ABG in the morning on ventilation. It should be appreciated that $\mathrm{Sp}, \mathrm{O}_{2}$ is only useful in determining the adequacy of ventilation if the patient is ventilated on air with or without little $\mathrm{O}_{2}$ supplementation. $\mathrm{O}_{2}$ supplementation can mask desaturation related to poor quality ventilation, and hypoventilation will not be recognised and corrected. Continuous $\mathrm{CO}_{2}$ monitoring in adults during NIV is problematic. End-tidal $\mathrm{CO}_{2}$ or transcutaneous $\mathrm{CO}_{2}$ can give some trends but both have significant limitations, and measurement of $\mathrm{ABG}$ remains essential. In cases of insufficient correction of hypoventilation, complementary monitoring can be carried out during the night, including thoracic abdominal movements, pressure and flow monitoring measured with a pneumotachograph close to the mask, evaluation of leaks and sometimes sleep quality. This monitoring will help to adjust ventilation, change the mode or the settings of ventilation (pressure support to pressure control or flow control) and/or the interface (nasal to mouth piece or facial mask). Some authors recommend initiating NIV in a sleep laboratory. The reasons for this practice include: NIV is usually used during sleep, sleep- disordered breathing is frequent in this patient population and finally the efficiency of NIV can be variable during sleep depending on levels of leaks, upper airway obstruction and central apnoea induced by ventilation [15].

In ARF these monitoring techniques are more important, as they are needed to recognise problems early. Failure of NIV should never lead to death, unless invasive ventilation is disclosed, but to intubation. Therefore, increasing $\mathrm{CO}_{2}$ and expiratory tidal volume should result in leak management, and if not possible, in intubation. Saturation should be used to detect accumulation of secretion if the arterial $\mathrm{O}_{2}$ saturation decreases despite sufficient ventilation. Sedation should be restricted or avoided so that the patient's cooperation and ability to cooperate can be monitored. This requires a different structure and organisation of intensive care and specialisation in respiratory care problems. And it requires profound knowledge on respiratory physiology and the evolution of respiratory disorders. Respiratory failure should not be considered as a sole problem separate from the underlying chronic disease. Decisions on intensive care should only be made in consideration of the disease's evolution. [9, 15].

\section{Home care organisation}

This type of organisation is not available in every European country, but should be recommended. In some countries home management is directly related to the hospital where NIV is implemented. More and more frequently, however, private home care companies are coming into existence; some for profit some not. Their activity is regulated by the health authority, which also set the level of reimbursement. Social security and/or private insurance will pay to provide and maintain medical equipment for the time the patient is at home.

These organisations include administrative, technical and paramedical staff, but do not practise daily care. Their role is to furnish and install equipment, according to a medical prescription, and they also usually settle the formalities with insurance companies or social security. They may educate the patient and/ or family and helpers about the use of the mask and the ventilator or reinforce information provided by the hospital. They can educate any caregivers, professional or not, who provide daily home care to the 
patient. They provide back-up in case of technical failure $24 \mathrm{~h}$ per day and technicians and/or nurses to make regular home visits for maintenance of the equipment and evaluation of its utilisation. The frequency of these visits should be based on the type of machine and on how the patient is getting on with NIV.

The first month is the most important and several visits may be necessary to adjust interfaces, settings, provide humidification if needed, as well as building patient confidence in using this technique in the home environment. In some cases the home care organisation is able to provide other facilities at home, for example nocturnal $\mathrm{Sp}, \mathrm{O}_{2}$ monitoring. Problems encountered at home are transmitted to the prescriber and good coordination with the hospital-based unit is essential; in particular it is essential that similar information is given to the patient by both and that there is a rapid and appropriate response from the hospital unit in case of any difficulty at home [10].

\section{Equipment and education}

The type of equipment used for NIV has been reviewed in a previous article in this series [16]. The package of equipment will depend upon the level of ventilator dependency of the patient and how easily they can access help in the case of equipment failure. For instance, patients living in remote locations will have different needs compared to those living near a home ventilation unit. A patient needing NIV $<12 \mathrm{~h} \cdot \mathrm{day}^{-1}$ will need a ventilator (alarms and batteries are not mandatory), circuit, two interfaces and in some cases some sort of humidification, although this is not usually necessary. More dependent patients $\left(>12-16 \mathrm{~h} \cdot \mathrm{day}^{-1}\right)$ will need a ventilator equipped with batteries and alarms and a reserve in case of machine failure. It is crucial that the patient and/or family/care givers be given adequate education regarding: interface placement, manoeuvres to limit leaks, placement of chinstrap if needed, procedures for cleaning interfaces and circuits and changing filters on the ventilator. They need to be told when to use their ventilator and for how long; this will usually be each night during sleep but sometimes it will be needed during the day, particularly if the patient has a nap. They should be taught how to recognise ventilator malfunction and other problems associated with NIV, e.g. exhalation valve failure, and how to remedy them. Advice should be given about routine maintenance, which can be performed by the patient and/or their carers, e.g. filter changes, washing of interfaces and head straps. Special advice is needed about what to do during an exacerbation; if patients have an upper respiratory tract infection, nasal blockage may make ventilation difficult at a time when it is more "necessary" than usual. Short-term use of nasal decongestant and steroid drops may be helpful. Advice should be given about when to seek further medical input, to increase NIV duration and the procedure to access hospital care when necessary. Verbal instruction should be reinforced by the provision of easy-to-understand written instructions, which can be personalised to the individual. Such documentation may be very useful if the patient is admitted to another hospital in an emergency. It is important that the family doctor be kept well informed; a patient on home ventilation will be unusual for most and it is vital that they be given adequate information and ready access to specialist help when necessary [17]. Secretion clearance is often neglected and education on how to use the ventilator to enhance secretion clearance, e.g. breath stacking, should be provided. Finally, an Ambu bag, with correct connections, should be provided for emergency use in more dependent patients, in case of ventilator failure and can be useful for others as a means of increasing cough efficiency by breath stacking [18] (tables 1 and 2).

During acute exacerbation, NIV of the awake patient will not be well tolerated with the conventional intensive care ventilators. Unnecessary alarms, caused by leaks, minor flexibility, modes that are not tolerated without sedatives, impede patient-orientated management. Several intensive care ventilators with features for NIV have been developed and introduced.

Table 1. - What should be done at monitoring visits once patients are established on home noninvasive ventilation?

Check on adequacy of symptom control

Check arterial blood gas tensions

Check ventilator use

Assess any change in patient condition

Need for increased ventilatory support, change of settings or interface?

Change or evolution of disease which decreases effectiveness of ventilation? \# $^{*}$

Reinforce previous education in ventilator use, troubleshooting, what to do in case of exacerbation

Repeat education and encourage practise of secretion clearance techniques when appropriate ${ }^{+}$

Further investigation may be indicated by results of above Spirometry and/or mouth pressures

Overnight monitoring of $\mathrm{Sp}_{\mathrm{p}} \mathrm{O}_{2}$ and $\mathrm{CO}_{2}$

More detailed overnight monitoring (respiratory

variables, full polysomnography)

Chest radiography

Swallowing assessments

Secretion removal

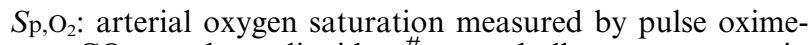
try; $\mathrm{CO}_{2}$ : carbon dioxide. ${ }^{\#}$. e.g. bulbar symptoms in amyotrophic lateral sclerosis; ${ }^{\circ}$ : emergency plan; ${ }^{+}$: e.g. neuromuscular patients.

Table 2. - Patient/carer education for noninvasive ventilation (NIV)

Rationale of NIV

Time and duration of use

How to spot and correct problems

What to do in case of machine failure

Routine maintenance (filter changes, interface washing etc.)

When and how to access hospital care

What to do during an exacerbation (emergency plan) 


\section{Funding}

The mechanism of reimbursement varies enormously from country to country and even from region to region. Data from the USA [19] suggest that establishing a patient on home ventilation may be achieved at a considerable loss to the initiating institution when reimbursement is on the basis of diagnosis related group. There is an urgent need for the true costs of chronic NIV to be adequately assessed [20]. It is important to budget for staff time costs as well as the cost of the ventilator and consumables. For instance, although customised masks may appear cheaper than industrial masks if only the cost of the raw materials is taken into account, this advantage soon disappears when the time taken by an experienced practitioner to make the mask is taken into account. Similarly, routine maintenance and emergency repairs should also be included within the budget. The cost of electricity, based on the equipment and its daily use, is also frequently included and reimbursed, but this is not always the case.

During ARF, NIV has been shown to need equal time consuming over time compared to invasive ventilation and thus it should be equally reimbursed. If successful, however, complications and in-hospital stay are less.

\section{Follow-up}

A harmonised European law calls for the ventilator to be serviced and checked either at predetermined intervals or after a certain number of hours of use. The need for servicing is less frequent with newer machines. Correct pressure and flow outputs should be verified, and the circuit should be checked for leaks and, when present, correct functioning of the exhalation valve. The interface should be inspected for any cracks or other damage and the pliability of the cushion checked. Over time, the quality of the head gear fastenings, usually Velcro, will deteriorate resulting in the mask working loose more easily with continued use. The head gear should be replaced at regular intervals depending upon duration of patient use, frequency of washing etc.

There are no data about how frequently the patient should be seen by a doctor at the specialist centre and in many respects this will depend upon the patient's diagnosis, their adaptation to NIV, their carers and ease of access to the hospital. Furthermore, if a home care company is involved, some of the follow-up can be performed in the patient's home with information transmitted back to the prescriber. The use of telemonitoring can be used to check compliance, ventilator performance etc. Although this is not widely available at present, it is likely to increase in the future. When a home care company is involved and they have paramedical staff, patient symptoms, quality of life, adverse effects related to ventilation and compliance can be systematically checked approximately every 3 months or according to the prescription. This information can be transmitted to the prescriber and any adjustments made. Some tests can only be performed in hospital and some form of hospital follow-up will usually be necessary. In one survey, patients on NIV had an average of three outpatient clinic visits per year in $78 \%$ of the units. Complementary exams for follow-up in these consultations included ABG in $98 \%$, chest radiographs in $44 \%$ and respiratory function tests in $54 \%$. Nocturnal evaluation at home, if possible, or in hospital to control the quality of ventilation at night is recommended after the first 3 months [11]. Overnight followup in the patient's first year after initiation of NIV evaluation was provided in $98 \%$ in the units involved in the survey. This evaluation included $S \mathrm{p}, \mathrm{O}_{2}$ monitoring in $72 \%$ of patients, polygraphy in $16 \%$, polysomnography in $10 \%$ and morning $\mathrm{ABG}$ in $83 \%$ [11]. For a large number of restrictive patients, once they are stabilised on ventilation, only minimal medical supervision is needed. Patients unstable and or insufficiently stabilised with NIV need more input (for instance those with rapidly progressive neuromuscular disease such as amyotrophic lateral sclerosis and to a lesser degree patients with duchenne muscular dystrophy and COPD).

In conclusion, noninvasive ventilation should be available in or to all hospital units which have the potential for treating patients with acute and chronic respiratory failure. The success of noninvasive ventilation is clearly linked to the experience and training of the team and the ability to provide adequate monitoring for the patient. In spite of a clear expansion of noninvasive ventilation in Europe, there remains no formal education for physicians or allied healthcare professionals in this technique. Arrangements for funding and reimbursement are poorly developed in many countries and there is often no formal infrastructure.

\section{References}

1. Bott J, Carroll MP, Conway JH, et al. Randomised controlled trial of nasal ventilation in acute ventilatory failure due to chronic obstructive airways disease. Lancet 1993; 341: 1555-1557.

2. Kramer N, Meyer TJ, Meharg J, Cece RD, Hill NS. Randomized, prospective trial of noninvasive positive pressure ventilation in acute respiratory failure. Am J Respir Crit Care Med 1995; 151: 1799-1806.

3. Brochard L, Mancebo J, Wysocki M, et al. Noninvasive ventilation for acute exacerbations of chronic obstructive pulmonary disease. N Engl J Med 1995; 333: 817-822.

4. Martin TJ, Hovis JD, Costantino JP, et al. A randomized, prospective evaluation of noninvasive ventilation for acute respiratory failure. Am J Respir Crit Care Med 2000; 161: 807-813.

5. Celikel T, Sungur M, Ceyhan B, Karakurt S. Comparison of noninvasive positive pressure ventilation with standard medical therapy in hypercapnic acute respiratory failure. Chest 1998; 114: 1636-1642.

6. Plant PK, Owen JL, Elliott MW. Early use of non invasive ventilation in acute exacerbations of chronic obstructive pulmonary disease on general respiratory 
wards: a multicenter randomised control trial. Lancet 2000; 355: 1931-1935.

7. Doherty MJ, Greenstone MA. Survey of non invasive ventilation (NIPPV) in patients with acute exacerbations of chronic obstructive pulmonary disease (COPD) in the UK. Thorax 1998; 53: 863-866.

8. Carlucci A, Richard JC, Wysocki M, Lepage E, Brochard L. Noninvasive versus conventional mechanical ventilation. An epidemiologic survey. $A m J$ Resp Crit Care Med 2001; 163: 874-880.

9. Elliott M, Confalonieri M, Nava S. Where to perform noninvasive ventilation? Eur Respir J 2002; 19: 11591166.

10. Leger P. Organisation of long term mechanical ventilation in Europe. In: Simonds AK, ed. Non invasive Respiratory Support. London, Chapman and Hall Medical, 2001; pp. 271-281.

11. Guiton C, Ordronneau J, Chollet S, Veale D, Coisy-Vialettes M, Chailleux E. French national survey on the practice of domiciliary non invasive ventilation. Am J Respir Crit Care Med 2000; 161: 3: A555.

12. Leger P, Bedicam JM, Cornette A, et al. Nasal intermittent positive pressure ventilation. Long-term follow-up in patients with severe chronic respiratory insufficiency. Chest 1994; 105: 100-105.

13. Simonds AK, Elliott MW. Outcome of domiciliary nasal intermittent positive pressure ventilation in restrictive and obstructive disorders. Thorax 1995; 50: 604-609.

14. Wedzicha JA, Muir J-F. Noninvasive ventilation in chronic obstructive pulmonary disease, bronchiectasis and cystic fibrosis. Eur Respir J 2002; 20: 777784.

15. Piper AJ, Sullivan CE. Effects of long term nocturnal nasal ventilation on spontaneous breathing during sleep in neuromuscular and chest wall disorders. Eur Respir J 1996; 9: 1515-1522.

16. Schönhofer B, Sortor-leger S. Equipment needs for noninvasive mechanical ventilation. Eur Respir J 2002; 20: 1029-1036.

17. Mechanical ventilation beyond the intensive care unit: report of a consensus conference of the American College of Chest Physicians. Chest 1998; 113: Suppl. 5, 289S-344S.

18. Kang S-W, Bach JR. Maximum insufflation capacity. Chest 2000; 118: 61-65.

19. Criner GJ, Kreimer DT, Tomaselli M, Pierson W, Evans D. Financial implications of non invasive positive pressure ventilation (NPPV). Chest 1995; 108: 475-481.

20. Nava S, Evangelisti I, Rampulla C, Compagnoni ML, Fracchia C, Rubini F. Human and financial costs of non invasive mechanical ventilation in patients affected by COPD and acute respiratory failure. Chest 1997; 111: 1163-1168. 